\title{
PENERAPAN KONSEP BANGUNAN NOL SAMPAH PADA DESAIN FASILITAS PENGOLAHAN SAMPAH DI MUARA ANGKE
}

\author{
Alvin Pranata ${ }^{1)}$, Stephanus Huwae ${ }^{2)}$ \\ 1)Program Studi S1 Arsitektur, Fakultas Teknik, Universitas Tarumanagara, pranata.vin@gmail.com \\ 2) Program Studi S1 Arsitektur, Fakultas Teknik, Universitas Tarumanagara, stephanush@ft.untar.ac.id
}

\begin{abstract}
Abstrak
Salah satu permasalahan ekologis di Indonesia adalah sampah. Dalam menghadapi permasalahan tersebut, diperlukan fasilitas pengolahan yang memadai, serta kesadaran manusia untuk mengurangi sampah. Pengolahan sampah dapat dilakukan dengan mendaur ulang menjadi barang berguna, merubah sampah menjadi sumber energi listrik, atau menjadi pupuk organik dengan menerapkan sistem nol sampah atau "zerowaste". Diperlukan bangunan yang dapat menjalankan proses - proses tersebut dan memberikan edukasi terhadap masyarakat tentang pentingnya mengurangi dan mengolah sampah. Arsitektur berkontribusi untuk mempersiapkan, merencanakan dan merancang bangunan yang akan digunakan. Diperlukan metode - metode untuk menciptakan fasilitas pengolahan sampah dengan memperhatikan lingkungan dan kawasan lokasi tapak. Pendekatan pragmatik digunakan sebagai dasar untuk memposisikan bangunan dalam menyelesaikan permasalahan ekologis sampah. Penerapan metode kontekstual diperlukan untuk membentuk aktivitas dalam proyek dengan memperhatikan kondisi tapak dan lingkungan lokasi proyek berada. Konsep visualisasi desain bangunan ini menggunakan konsep arsitektur teknologi tinggi untuk memperlihatkan utilitas pengolahan sampah, sistem pengolahan sampah, penggunaan material hasil daur ulang yang ringan, kokoh, efektif dan efisien. Keberhasilan proyek ini dapat dicapai melalui (1) pengolahan sampan dengan sistem nol sampah; (2) aktivitas yang terbentuk didalam proyek; (3) kebutuhan dan hubungan ruang yang fleksibel, efektif dan efisien; (4) aksesibilitas dan sirkulasi. Diharapkan proyek ini dapat mengatasi permasalahan ekologis sampah tanpa menghasilkan sampah lain, memberikan edukasi kepada masyarakat tentang pentingnya mengurangi dan mengolah sampah serta menjadikan proyek ini sebagai salah satu pusat aktivitas untuk pemenuh kebutuhan masyarakat.
\end{abstract}

Kata kunci: Daur Ulang; Fasilitas Pengolahan Sampah; Metode Kontekstual; Pendekatan Pragmatik; Sistem Nol Sampah

\begin{abstract}
One of the ecological problems in Indonesia is waste. In dealing with these problems, adequate processing facilities are needed, as well as human awareness to reduce waste. Waste processing can be done by recycling it into useful goods, converting waste into a source of electrical energy, or into organic fertilizer by implementing a zero waste or "zerowaste" system. Buildings are needed that can carry out these processes and provide education to the public about the importance of reducing or processing waste. Architecture contributes to preparing and designing buildings that will be used. Methods are needed to create waste processing facilities by taking into account the environment and the area where the site is located. The pragmatic approach is used as the basis for positioning the building in solving the ecological problems of waste. The application of contextual methods is needed to shape activities in the project by taking into account the site conditions and the environment where the project is located. This building design visualization concept uses high-tech architectural concepts to show the utility of waste processing, waste processing systems, the use of recycled materials that are lightweight, sturdy, effective and efficient. The success of this project can be achieved through (1) waste treatment with zero waste system; (2) activities formed in the project; (3) flexible, effective and efficient space
\end{abstract}


requirements and relationships; (4) accessibility and circulation. It is hoped that this project can overcome the ecological problems of waste without producing other waste, provide education to the community about the importance of reducing and processing waste and make this project a center of activity to meet the needs of the community.

\section{Keywords: Contextual Method; Pragmatic Approach; Recycling; Waste Treatment Facilities; Zerowaste System}

\section{PENDAHULUAN}

\section{Latar Belakang}

Salah satu permasalahan ekologis saat ini adalah sampah yang akan selalu meningkat bersamaan dengan kebutuhan masyarakat yang semakin berkembang. Sedangkan lahan tidak bertambah dengan berjalannya waktu. Menurut Kementerian Koordinator Bidang Kemaritiman dan Investasi Indonesia (2017), Indonesia adalah negara kepulauan dengan jumlah 17.504 pulau dan terdapat 1.448 pulau yang belum ter-verifikasi. Sehingga, Indonesia sangat rentan sekali terhadap polusi air dan $70 \%$ sampah plastik berpotensi masuk ke lautan Indonesia. Menurut Ropesta Sitorus (2019), Pemerintah Indonesia mengatakan bahwa Indonesia merupakan penghasil sampah terbesar kedua di dunia dengan jumlah 64 juta ton per tahunnya dan mengalami kenaikan kisaran 0,27 - 0,59 juta ton sampah per tahun. Hal ini akan merusak lingkungan baik darat,air, maupun udara. Banyak penanganan sampah yang sudah dilakukan tetapi tetap menghasilkan bentuk sampah lainnya. Sehingga masih dianggap belum efektif dan efisien dalam mengurangi jenis sampah yang ada. Maka dari itu diperlukan bangunan fasilitas pengolahan sampah yang dapat menampung dan mengolah sampah menjadi barang berguna atau energi untuk kebutuhan masyarakat tanpa menghasilkan jenis sampah lainnya.

Solusi permasalahan sampah plastik dengan menerapkan sistem zerowaste merupakan cara untuk mengurangi polusi yang disebabkan oleh sampah baik di darat,laut, maupun udara. Dengan menerapkan 3 cara yaitu, daur ulang sampah menjadi barang berguna, pembakaran sampah menjadi energi listrik, dan sisa abu pembakaran dijadikan campuran bahan bangunan pengganti pasir. Penerapan visualisasi desain Arsitektur High-Tech dilatarbelakangi dari konteksktual kawasan. Dengan memanfaatkan penggunaan bahan daur ulang sampah pada eksterior dan interior serta penerapan desain Arsitektur High-Tech, cara ini menjadi salah satu penyelesaian pengurangan sampah dengan edukasi. Dimana terdapat berbagai kriteria dari Arsitektur High-Tech yang memunculkan bagaimana pengolahan sampah dapat dijadikan edukasi untuk masyarakat sekitar.

Kawasan Muara Angke dipilih menjadi tempat pelaksanaan proyek, karena berada di muara sungai DKI Jakarta dengan kepadatan penduduk yang cukup tinggi serta produksi sampah yang tidak sesuai dengan cukupnya lahan penampungan yang didaerah tersebut. Selain itu, Muara Angke menjadi tempat menumpuknya sampah yang berasal dari beberapa sungai di DKI Jakarta seperti Kali Krukut, Kali Baru Barat, dan Kali Ciliwung. Ditambah dengan kurangnya edukasi tentang kesadaran masyarakat tentang sampah dikawasan ini, Dikhawatirkan Muara Angke akan menjadi lautan sampah dan menyebabkan pencemaran air yang berlebihan dan mematikan habitat perairan didaerah tersebut. Sehingga, untuk mengembalikan kawasan Muara Angke menjadi kawasan bebas sampah digunakan metode pragmatis, kontekstual dengan pendekatan metode Arsitektur High-Tech untuk merancang fasilitas pengolahan sampah dengan sistem zerowaste.

\section{Rumusan Permasalahan}

Sampah adalah salah satu sisa barang yang tidak bisa dihilangkan dan akan terus bertambah sesuai dengan kebutuhan masyarakat. Agar sampah tidak menumpuk dan dapat digunakan kembali, diperlukan adanya fasilitas yang dapat menampung dan mengolah sampah tersebut 
menjadi barang atau energi yang berguna. Muara Angke merupakan daerah yang pada dengan penduduk. Hal tersebut menyebabnya kurangnya lahan untuk menampung sampah di kawasan tersebut. Sehingga banyak sampah dari penghuni Muara Angke membuangnya ke sungai yang ada disekitar atau menimbunnya di depan rumah. Tidak hanya itu, kurangnya kesadaran masyarakat DKI Jakarta juga mempengaruhi menumpuknya sampah di muara sungai. Oleh karena itu identifikasi masalah pada perancangan ini yaitu, permasalahan sampah yang menumpuk di muara sungai angke yang menyebabkan polusi bagi habitat perairan di daerah yang kebutuhannya bertambah dengan pesat dan belum ada kesadaran diri dari masyarakat.

Fasilitas pengolahan sampah ini menerapkan prinsip "zerowaste" dengan memaksimalkan pengolahan sampah secara efektif untuk mengurangi polusi. Dengan menerapkan 3 cara dalam pengolahan sampah yaitu, daur ulang sampah menjadi barang berguna, pembakaran sampah menjadi energi listrik, dan mengolah sisa abu pembakaran menjadi campuran bahan bangunan pengganti pasir. Selain itu juga, kebutuhan energi pada fasilitas ini diperlukan, sehingga dibutuhkan konsep bangunan mandiri dengan menggunakan sistem incinerator untuk membantu memproduksi sampah menjadi energi listrik. Penerapan visualisasi desain Arsitektur High-Tech juga digunakan dalam eksterior dan interior bangunan dalam membantu pengurangan sampah melalui edukasi. Penelitian ini berfokus untuk memberikan sebuah fasilitas pengolahan sampah yang dapat memaksimalkan berbagai jenis sampah menjadi barang dan energi berguna, menciptakan energi mandiri bagi proyek bangunan, serta memberikan edukasi bagi masyarakat sekitar tentang pentingnya mengurangi dan mengolah sampah.

\section{Tujuan}

Menjawab persoalan sampah perairan dan sekitar untuk masa depan Kawasan Muara Angke serta di DKI Jakarta terkait sampah di sungai dengan konsep bangunan mandiri yang menerapkan "zerowaste" terhadap pengolahan sampah tersebut.

\section{KAJIAN LITERATUR Ekologi (Ecology)}

Berdasarkan buku yang diterbitkan oleh Universitas Terbuka yang berjudul Ekologi bagian Pengertian, Ruang Lingkup Ekologi dan Ekosistem (2014: 3), Ekologi adalah ilmu tentang hubungan timbal balik antara makhluk hidup dan lingkungannya. Kata ekologi pertama kali diperkenalkan oleh Ernst Haeckel seorang ahli biologi Jerman pada tahun 1866. Beberapa para pakar biologi pada abad ke 18 dan 19 juga telah mempelajari bidang-bidang yang kemudian termasuk dalam ruang lingkup ekologi. Misalnya Anthony van Leeuwenhoek, yang terkenal sebagai pioner penggunaan mikroskop, juga pioner dalam studi mengenai rantai makanan dan regulasi populasi. Bahkan jauh sebelumnya, Hippocrates, Aristoteles, dan para filosuf Yunani telah menulis beberapa materi yang sekarang termasuk dalam bidang ekologi.

\section{Ekosistem (Ecosystem)}

Berdasarkan buku Susanto,S (2017: 5), Ekosistem merupakan hubungan timbal balik yg kompleks antara organisme \& lingkungannya baik yg hidup maupun yg tidak hidup yg secara bersama membentuk suatu sistem ekologi. Istilah ekosistem pertama kali dipakai oleh Tansley pada tahun 1935. Penulis lain menggunakan istilah berbeda untuk maksud yang sama seperti mikrokosm oleh Forbs (1887), holocoen oleh Friederich (1930), biosistem oleh Thenemann (1939), dan bionert body oleh Vernadsky (1944).

\section{Manusia sebagai Bagian dari Ekologi (Human as a part of Ecology)}

Manusia merupakan bagian dari ekosistem yang merupakan ilmu ekologi. manusia pada biosphere bumi ini memiliki peran penting tentang ekologi. Pada awalnya peran manusia dalam ekologi dan dalam sejarah manusia, hanya menjadi bagian dari ekologi bumi ini, setingkat 
dengan hewan dan tanaman, berbeda dengan kondisi manusia modern saat ini. Dimana pada awalnya manusia merupakan predator mangsa lain sebagai pemenuh kebutuhan hidup mereka.

Meningat manusia merupakan individu yang terus berkembang dan mementingkan diri sendiri. Pada akhirnya manusia akan sadar bahwa bumi sedang terjadi krisis terhadap ekosistem. Sehingga hal tersebut akan menjadi tugas manusia dalam menghadapi krisis ekosistem tersebut.

\section{Habitat (Habitat)}

Menurut KBBI Daring yang diterbitkan oleh Kementrian Pendidikan dan Kebudayaan Republik Indonesia (2016), Habitat adalah tempat suatu makhluk hidup tinggal dan berkembang biak. Pada dasarnya, habitat adalah lingkungan-lingkungan fisik-di sekeliling populasi suatu spesies yang memengaruhi dan dimanfaatkan oleh spesies tersebut.

\section{Habitat dan Ekologi (Habitat and Ecology)}

Menurut Clements dan Shelford dalam buku nya yang berjudul Bio-Ecology (1939), habitat adalah lingkungan fisik yang ada di sekitar suatu spesies, atau populasi spesies, atau kelompok spesies, atau komunitas. Dalam ilmu ekologi, bila pada suatu tempat yang sama hidup berbagai kelompok spesies (mereka berbagi habitat yang sama) maka habitat tersebut disebut sebagai biotop. Terdapat beberapa golongan habitat: hutan rimba, hutan kecil, gurun, lereng pegunungan, kolam, sungai, rawa, dan laut. Habitat yang lebih luas seperti padang belantara atau hutan hujan dinamakan Bioma. Bioma adalah sekelompok tumbuhan dan hewan yang tinggal di suatu habitat pada suatu lokasi geografis tertentu.

\section{Sampah (Waste)}

Dalam jurnal yang ditulis oleh Hayat dan Hasan (2018: 133), mengatakan definisi sampah menurut World Health Organization (WHO) adalah sesuatu yang tidak digunakan, tidak dipakai, tidak disenangi atau sesuatu yang dibuang yang berasal dari kegiatan manusia dan tidak terjadi dengan sendirinya (Chandra, 2006).

Pada masa ini, sampah menjadi salah satu masalah ekologi terberat yang sulit diselesaikan di beberapa negara. Hal ini dikarenakan masih kurangnya fasilitas memadai untuk pengelolaan sampah tersebut serta kurangnya kesadaran dari manusia untuk mengatur sampah tersebut.

\section{Melampaui Ekologi dan Melampaui Arsitektur (Beyond Ecology and Beyond Architecture)}

Berdasarkan materi presentasi Suwardhana Winata tentang eco-logic (2020), Hubungan ekologi dan arsitektur adalah Ekologi berasal dari kata oikos memiliki arti house-rumah dan logia atau ilmu. Kata eko atau oikos ini merupakan kata yang sangat penting bila dikaitkan dengan arsitektur karena memiliki makna rumah atau house. Beyond ecology adalah suatu sistem biologi yang digunakan untuk menyelesaikan atau melihat atau menganalisis suatu fenomena non biologi.

Arsitektur merupakan karya manusia yang berusaha untuk membentuk suatu sistem yang dapat berhubungan dengan ekosistem yang ada (alam). Arsitektur merupakan sistem yang sengaja disusun dan dirancang agar dapat menjadi bagian dari ekosistem alam yang sudah ada terlebih dahulu, namun dalam prakteknya arsitektur terkadang berusaha "mengalahkan" atau "mendominasi" bahkan "menguasai" ekosistem alam yang lebih dulu ada.

\section{Habitat dan Sampah (Habitat and Waste)}

Dalam buku Ecological X-Files: Proof that Aliens are Destroying Endangered Species, Environmental Defense Fund (1998), Kehilangan habitat menduduki ranking tertinggi sebagai 
ancaman serius bagi kematian spesies dan keanekaragaman hayati di dalam hutan, kehilangan habitat memiliki kontribusi $85 \%$ atas hilangnya berbagai jenis spesies. Lalu, dari segi penggunaan lahan dan perkembangan, Pertanian dan pembangunan diidentifikasi sebagai penyebab paling luas yang menyebabkan hilangnya habitat untuk kehidupan liar, mempengaruhi $38 \%$ kehidupan spesies, dan baru diikuti pembangunan sebesar $35 \%$, lalu pembangunan perairan $30 \%$.

\section{Nol Limbah (Zerowaste)}

Menurut Zero Waste International Alliance, definsi Zerowaste adalah Konservasi semua sumber daya melalui produksi, konsumsi, penggunaan kembali, dan pemulihan semua produk, pengemasan, dan bahan yang bertanggung jawab tanpa membuangnya ke tanah, air, atau udara yang mengancam lingkungan atau kesehatan manusia/menghasilkan limbah lainnya.

\section{Arsitektur Teknologi Tinggi (High-Tech Architecture)}

Arsitektur Teknologi Tinggi/High-Tech Architecture adalah gaya perancangan bangunan dengan standar tertentu yang diatur dan ditata sedemikian rupa. Tujuannya, yaitu untuk memecahkan masalah yang ada dengan pemakaian bahan bangunan yang fungsional dan estetis. Bangunan dengan arsitektur High-Tech biasanya terbuat dari material sintetis seperti logam, kaca dan plastik. Menurut Collin Davis dalam bukunya yang berjudul High-Tech Architecture (1988), Pengertian High-Tech dalam arsitektur berbeda dengan maknanya dalam industri. Bila dalam industri High-Tech diartikan sebagai teknologi canggih seperti elektronik, robot, computer, biji silikon, mobil sport dan sejenisnya. Sedangkan dalam arsitektur High-Tech diartikan sebagai suatu aliran arsitektur yang bermuara pada ide gerakan arsitektur modern yang membesarbesarkan kesan struktur dan teknologi suatu bangunan. Konsep visualisasi bangunan High-Tech Architecture didukung oleh beberapa kriteria yang dibuat untuk membantu efisiensi, efektivitas, dan ciri khas dari suatu bangunan dengan menggunakan bahan-bahan yang ringan, mudah didapat, fungsional dan tidak menghasilkan sampah bagi bangunan itu sendiri.

\section{METODE}

\section{Pendekatan Pragmatik (Pragmatic Approach)}

Berdasarkan Artikel yang ditulis Keren E. Manaroinsong dan Suryono, Metode Pragmatik menekankan pada menyelesaikan satu atau beberapa masalah tertentu yang nyata dan terukur, misal: iklim, keterbatasan lahan, dana, waktu pembangunan, bahan bangunan dan/atau konstruksi spesifik. Konsep ini dikembangkan berkisar persoalan-persoalan yang pragmatis yang diidentifikasi dari program sebuah bangunan. Konsep ini merupakan tanggapan langsung dari pemecahan masalah.

\section{Metode Kontekstual (Contextual Method)}

Berdasarkan buku Design Method dari Karl Jormakka (2003: 62), Metode ini menekankan bahwa sebuah bangunan harus mempunyai kaitan dengan lingkungannya. Keterkaitan tersebut membuat hubungan yang erat antara proyek yang akan dibuat dengan kesinambungan dengan lingkungan sekitarnya yang terlebih dulu ada. Metode ini membuat perancangan proyek didasari oleh lingkungan yang telah ada sehingga hasil bentuk proyek tidak merusak citra dari lingkungan dan menyatu dengan lingkungan yang sudah terlebih dulu ada.

\section{Keterkaitan Zerowaste Building dengan Metode Visualisasi Arsitektur Teknologi Tinggi/High- Tech Architecture}

Keterkaitan antara zerowaste building dengan visualisasi arsitektur terdapat dari bagaimana bangunan dengan konsep Arsitektur High-Tech mengaplikasikan zerowaste building. Teknologi Arsitektur High-Tech yang dimaksud dalam proyek ini adalah penggunaan teknologi pengolahan sampah dalam mempersiapkan ruang - ruang yang dibutuhkan untuk teknologi tersebut, serta penggunaan bahan jadi dari pengolahan sampah untuk kebutuhan bangunan. Baik penggunaan 
pada fasad, ataupun energi bangunan. Selain itu, kriteria dari Arsitektur teknologi tinggi juga ditujukan untuk mengedukasi masyarakat sekitar tentang pentingnya mengurangi, dan mengolah sampah.

Terdapat 6 kriteria High-Tech Architecture dan 3 kriteria yang ditambahkan oleh Richard Rogers dalam mendesain bangunan berkonsep ini dalam memenuhi kebutuhan, baik untuk fasilitas, kontekstual kawasan dan edukasi masyarakat yang akan diaplikasikan dalam proyek perancangan fasilitas pengolahan sampah ini. Kriteria utama yang diangkat yaitu, inside out, celebration of process, transparency-layering-movement, flat bright color, a lightweight filigree of tensile member, dan optimistic confidence in scientific culture. Sedangkan 3 kriteria tambahan Richard Rogers berupa Efficiency, Impermanency-Flexibility, dan Lower-Energy. Dimana 8 kriteria tersebut diterapkan pada bangunan Fasilitas Pengolahan Sampah ini.

\section{Metode Perancangan (Design Method)}

Perancangan proyek ini menggunakan metode pragmatis dan kontekstual kawasan dengan penerapan bangunan zerowaste dan pendekatan Arsitektur High-Tech. Desain disesuaikan dengan tahap-tahap pengolahan dan penyelesaian sampah tanpa menimbulkan sisa sampah lainnya serta penyesuaian terhadap kebutuhan konteksktual kawasan. Karena proyek ini memiliki tujuan untuk pengolahan dan edukasi, proyek ini mengangkat istilah Arsitektur HighTech dalam mendesain. Perwujudan Arsitektur High-Tech diaplikasikan dengan prinsip zerowaste serta kriteria lain dalam Arsitektur High-Tech. Dimana dalam hal ini, perwujudan prinsip zerowaste dan kriteria Arsitektur High-Tech berupa bentuk massa yang futuristik, transparan, memperlihatkan struktur dan proses penggunaan material yang ramah lingkungan, menghasilkan energi dari hasil pengolahan sampah, serta efisiensi dalam penggunaan ruang dalam pengolahan sampah.

\section{DISKUSI DAN HASIL}

Proyek ini merupakan fasilitas pengolahan sampah yang berada di bibir sungai Muara Angke, Jakarta Utara. fokus dari fasilitas ini adalah menyelesaikan permasalahan sampah yang berasal dari sungai di DKI Jakarta yang berakhir di Muara Angke. Tapak berada di Muara Angke, Jl. Dermaga Ujung 1, Pluit, Kec. Penjaringan, Kota Jkt Utara, DKI Jakarta 14450. Kawasan Muara Angke memiliki kepadatan penduduk $7.337 \mathrm{jiwa} / \mathrm{km} 2$. Kawasan Muara Angke memiliki karakteristik pemukiman kumuh serta kawasan ini juga merupakan daerah penghasil pangan laut terbesar di Jakarta dengan kondisi masyarakat heterogen, multi etnis. Padatnya penduduk di Muara Angke menyebabkan produksi sampah yang juga bertambah. Padahal, lahan di Muara Angke sudah semakin berkurang. Tujuan proyek ini adalah membuat fasilitas pengolahan sampah dengan menerapkan sistem zerowaste. Dimana sampah yang diolah berasal dari sungai Kali Adem yang datang dari 3 sungai di DKI Jakarta seperti Kali Krukut, Kali Baru Barat, dan Kali Ciliwung. Selain itu juga fasilitas ini mengolah sampah yang berasal dari kawasan Muara Angke, Pluit. Pengolahan sampah di fasilitas ini menggunakan beberapa teknologi seperti inceptor, insinerator, dan pengolahan secara manual. Tidak hanya sebagai fasilitas pengolahan, proyek ini juga sebagai fasilitas edukasi terkait sampah bagi penduduk sekitar dengan memperhatikan kontekstual lingkungan. Sehingga dapat terbentuk aktivitas yang bisa menghidupkan proyek ini dan dapat beradaptasi dengan lingkungan.

\section{Analisis Makro Tapak}

Permasalahan utama berasal dari jumlah penduduk Jakarta, 10.557.810 jiwa di tanah seluas $7.659,02 \mathrm{~km} 2$. Padatnya penduduk membuat produksi sampah bertambah dengan cepat. Kurangnya pengelolaan sampah di Jakarta, membuat sampah tersebut menumpuk. Terutama di daerah pesisir laut atau muara sungai. Per-harinya, sampah di Jakarta mencapai 7.700 ton. Sehingga Jakarta memiliki kriteria daerah yang berpotensi mengalami penumpukan sampah 
yang akan merusak ekosistem perairan apabila tidak dihadapi dengan baik. DKI Jakarta dilalui 13 sungai yang semuanya bermuara di Teluk Jakarta. Belasan sungai tersebut mengalirkan air dari kawasan tinggi di sebelah selatan. Kenyataannya sungai difungsikan sebagai bak sampah. Sungai pun berubah fungsinya sebagai media pengantar sampah hingga ke teluk. Sehingga sampah di sungai akan menumpuk di sisi Jakarta Utara. Jumlah sampah diperairan mencapai 250-400 ton/hari di perairan seluas $20.428 \mathrm{~m} 2-28.453 \mathrm{~m} 2$.

Pemilihan site tepatnya berada di daerah Jakarta Utara. Dimana daerah Jakarta Utara merupakan daerah yang paling dekat dengan laut dan terdapat pemukiman kumuh yang berada di pesisir. Pemukiman kumuh dan padat tersebut merupakan sumber utama sampah yang menyebabkan ekosistem perairan menjadi tercemar. Tidak hanya dari situ, sampah yang berasal dari perkotaan yang dibuang sembarang ke sungai dan menumpuk di muara sungai Jakarta Utara juga menjadi penyebab ekosistem perairan tercemar. Terdapat beberapa daerah dengan sampah yang menumpuk di muara sungai, seperti di daerah Muara Angke, Cilincing, kanal Banjir Timur, dan Kapuk.

\section{Analisis Messo Tapak}

Muara Angke merupakan pemukiman yang terletak di kota Jakarta Utara diatas tanah seluas $140 \mathrm{~km} 2$. Daerah ini merupakan salah satu sumber penghasil pangan laut terbesar di Jakarta. Sebagai salah satu daerah penghasil pangan laut terbesar di Jakarta, Muara Angke menjadi padat akan penduduk karena kemudahannya memperoleh hasil laut. Kepadatan ini menyebabkan daerah tersebut menjadi pemukiman kumuh yang tidak terawat karena letaknya yang berada dengan pasar hasil pangan laut. Kepadatan penduduk ini berakibat pada produksi sampah yang dihasilkan daerah tersebut. Kurangnya lahan di daerah ini membuat daerah ini sulit memiliki TPA yang cukup untuk menampung sampah daerah tersebut. Sehingga masyarakat Muara Angke menumpuk sampah mereka sendiri, bahkan membuangnya ke pesisir pantai/sungai. Hal ini dapat menyebabkan pencemaran air yang akan merusak ekosistem perairan dan kualitas air bersih. Selain itu, kurangnya lahan membuat daerah ini tidak ramah lingkungan dan memiliki fasilitas yang memadai. Selain itu, saat ini sampah di Muara Angke berasal beberapa kali yang menyambung dengan Muara Angke. Yaitu, Kali Krukut, Kali Baru Barat dan Kali Ciliwung.

\section{Analisis Mikro Tapak}

Lokasi tapak berada di JI. Dermaga Ujung 1, Pluit, Kec. Penjaringan, Kota Jkt Utara, DKI Jakarta 14450. memiliki luas 12.800 meter persegi. Terletak di pesisir sungai dan laut dengan kepadatan penduduk yang tinggi. Kelurahan Pluit adalah kelurahan yang memiliki jumlah kependudukan 56.572 jiwa. Ditanah seluas 7,71 km2.

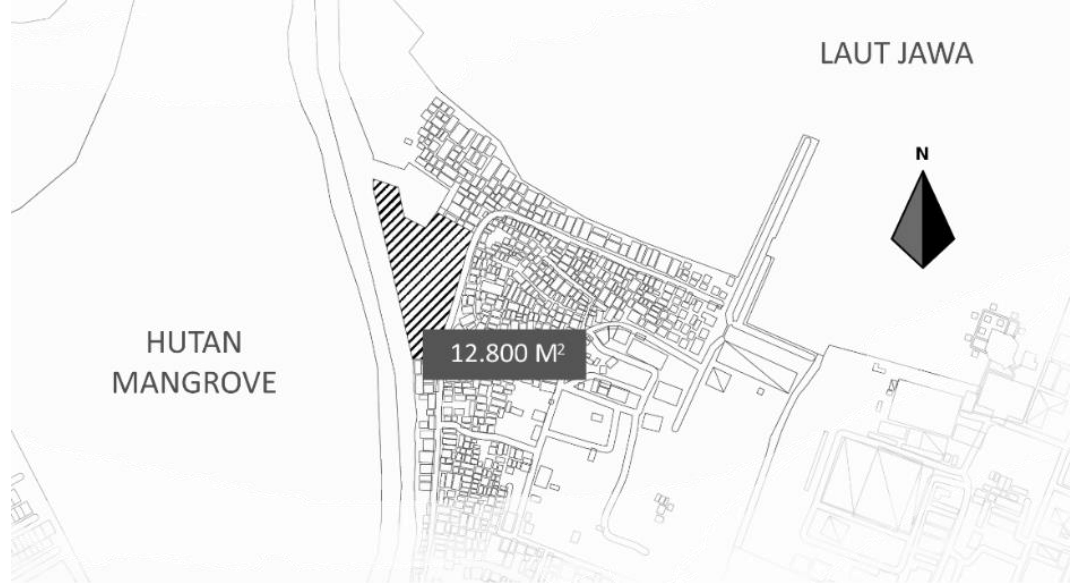

Gambar 1. Gambaran Sekitar Tapak

Sumber : Penulis, 2021 
Menurut website Jakarta Satu di halaman jakartasatu.jakarta.go.id, Tapak memiliki KDB 40\%, KLB 1.2, KDH 45\%, KB 4, DAN KTB 40\%. Merupakan zona perkantoran, perdagangan dan jasa. Kondisi tapak berdekatan dengan pemukiman warga Muara Angke. Disisi Utara dan Barat terdapat Hutan Mangrove. Pada daerah ini, tidak ada aktivitas industri melainkan bangunan hanya merupakan pemukiman warga dan juga dijadikan sebagai tempat pengolahan ikan. Hal ini menimbulkan limbah padat yang cukup besar didaerah ini terutama di pinggir sungai.

\section{Penerapan Konsep dan Program Bangunan Fasilitas Pengolahan Sampah di Muara Angke Jakarta}

Dalam mendesain bentuk, sirkulasi, dan zonasi pada proyek ini, hal yang diperhatikan berdasarkan kontekstual kawasan. Dimana dari analisis yang sudah dilakukan terhadap kawasan ini, diperlukan adanya fungsi tambahan berupa fasilitas edukasi dan fasilitas komersil lainnya. Dalam pengolahan sirkulasi bangunan, serta efektivitas dan efisiensi ruang, perlu diperhatikan bagaimana bangunan memiliki sirkulasi yang baik dalam mengolah sampah dan memberikan edukasi secara detail.

Fungsi pada bangunan ini dibagi menjadi 3 zonasi dengan kategori, Bangunan Utama/Semi Private (Waste Recycle Plan), Bangunan Publik dan Bangunan Edukasi/Bangunan Semi-Publik.

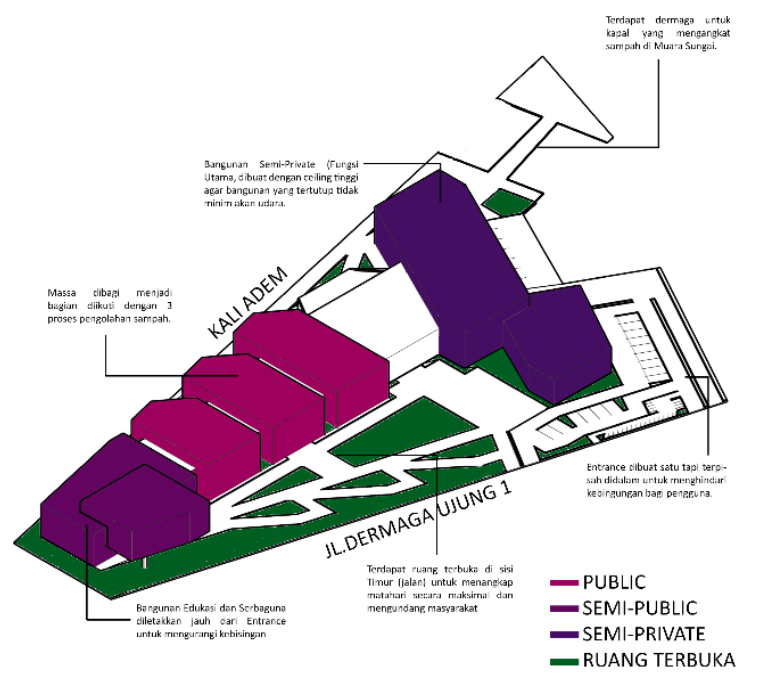

Gambar 2. Zonasi Pada Fungsi Bangunan

Sumber : Penulis, 2021

Dari hasil studi analisis kebutuhan ruang dan juga studi analisis kawasan sekitar, dihasilkan presentase fungsi ruang dan juga program ruang terhadap 3 zonasi pada bangunan untuk memenuhi kebutuhan aktivitas pada proyek. Perhitungan luas lahan $12.800 \mathrm{~m} 2$ dengan KDB $4.301 \mathrm{~m} 2$ dan KLB $2.308 \mathrm{~m} 2$. dengan presentase fungsi pada bangunan recycle plan $33 \%$, rekreasi $23 \%$, edukasi $23 \%$, komersil $13 \%$, dan penunjang serta service $11 \%$.

Konsep bentuk pada bangunan ini didasari dari analisis tapak dan juga dari garis bentuk tapak. Tabel diatas merupakan besaran program ruang yang dibutuhkan dalam membangun proyek ini.

Tabel 1. Program Ruang Recycling Center

PROGRAM RUANG RECYCLING CENTER

\begin{tabular}{llcrrrr} 
PROGRAM KEGIATAN & PROGRAM RUANG & KAPASITAS & JUMLAH & $\begin{array}{c}\text { LUAS } \\
\text { (M⿻) }^{2}\end{array}$ & $\begin{array}{c}\text { TOTAL } \\
\left.\text { (M⿻) }^{2}\right)\end{array}$ \\
\hline Persiapan & Lobby & 50 orang & 1 & 0,8 & 400 \\
\hline
\end{tabular}




\begin{tabular}{|c|c|c|c|c|c|}
\hline \multicolumn{6}{|c|}{ PROGRAM RUANG RECYCLING CENTER } \\
\hline PROGRAM KEGIATAN & PROGRAM RUANG & KAPASITAS & JUMLAH & $\begin{array}{l}\text { LUAS } \\
\left(\mathrm{M}^{2}\right)\end{array}$ & $\begin{array}{c}\text { TOTAL } \\
\left(\mathbf{M}^{2}\right)\end{array}$ \\
\hline & R.Persiapan 1 (Pengambilan Alat) & 10 orang & 1 & 1,5 & 15 \\
\hline & R.Persiapan 2 (Briefing) & 30 orang & 1 & 1 & 30 \\
\hline \multicolumn{6}{|c|}{ WASTE RECYCLE PLAN / FUNGSI UTAMA / SEMI PRIVATE } \\
\hline Interceptor & Pengambilan Sampah Perairan & 2 orang & 1 & 192 & 192 \\
\hline $\begin{array}{l}\text { Parkir Kapal } \\
\text { Pengangkut }\end{array}$ & Dermaga & & 2 & 63 & 126 \\
\hline Penampungan & Bak Penampungan & 400 ton & 1 & 192 & 192 \\
\hline \multirow[t]{7}{*}{ Daur Ulang Sampah } & Workshop & 10 orang & 1 & 4 & 40 \\
\hline & Pembakaran & & & 592 & 592 \\
\hline & Precipitator & & & & \\
\hline & Boiler & & & & \\
\hline & Generator & & & & \\
\hline & Kondensor & & & & \\
\hline & Penampungan Abu & & & & \\
\hline Sampah menjadi Pupuk & Green House & & 1 & 160 & 160 \\
\hline \multicolumn{6}{|c|}{ EDUCATIONAL / FUNGSI PENUNJANG / SEMI PUBLIC } \\
\hline Tur-Edukasi & View Deck & 30 orang & 1 & 2 & 60 \\
\hline \multirow[t]{3}{*}{ Mini Lab } & R. Penyimpanan Alat & 3 orang & 1 & 4 & 12 \\
\hline & Laboratorium & 3 orang & 1 & 4 & 12 \\
\hline & Area Kumpul & 12 orang & 1 & 0,8 & 9,6 \\
\hline \multirow[t]{3}{*}{ Outdoor Learning } & Amphitheater & 30 orang & 1 & 2,5 & 75 \\
\hline & Persiapan & 4 orang & 2 & 2,5 & 20 \\
\hline & Panggung & 4 orang & 1 & 8 & 32 \\
\hline \multirow[t]{5}{*}{ Exhibition/Serbaguna } & Foyer/Lobby & 100 orang & 1 & 1 & 100 \\
\hline & R.Persiapan & 6 orang & 2 & 2,5 & 30 \\
\hline & Toilet & 8 orang & 2 & 3 & 48 \\
\hline & R.Serbaguna & 120 orang & 1 & 1,5 & 121,5 \\
\hline & Gudang & 2 orang & 1 & 4 & 8 \\
\hline Informasi & Dinding Informasi & 4 orang & & 0,8 & 3,2 \\
\hline \multicolumn{6}{|c|}{ RECREATIONAL / FUNGSI PENUNJANG / PUBLIC } \\
\hline \multirow[t]{3}{*}{ Taman Relaksasi } & Taman Hijau & 100 orang & 1 & 4 & 400 \\
\hline & Events & & & & \\
\hline & Area Duduk & 25 orang & 2 & 4 & 200 \\
\hline Pasar Daur Ulang & Area Jualan & 10 orang & 1 & 3 & 30 \\
\hline Kuliner Kaki Lima & Area Jualan & 2 orang & 10 & 4 & 80 \\
\hline Area Pengunjung & Area Duduk & 30 orang & 2 & 2,5 & 150 \\
\hline Service & Toilet & 3 orang & 2 & 3 & 18 \\
\hline \multicolumn{6}{|c|}{ LAIN - LAIN / FUNGSI TAMBAHAN } \\
\hline \multirow[t]{3}{*}{ Lobby } & Resepsionis & 2 orang & 2 & 4 & 8 \\
\hline & Area Tunggu & 100 orang & 1 & 0,8 & 80 \\
\hline & R. Meeting & 10 orang & 1 & 2 & 40 \\
\hline \multirow[t]{3}{*}{ Kantor } & R. Staff & 6 orang & 2 & 6 & 72 \\
\hline & R. Manager & 2 orang & 2 & 6 & 24 \\
\hline & R. Pengelola & 2 orang & 2 & 6 & 24 \\
\hline
\end{tabular}




\begin{tabular}{|c|c|c|c|c|c|}
\hline \multicolumn{6}{|c|}{ PROGRAM RUANG RECYCLING CENTER } \\
\hline PROGRAM KEGIATAN & PROGRAM RUANG & KAPASITAS & JUMLAH & $\begin{array}{l}\text { LUAS } \\
\left(M^{2}\right)\end{array}$ & $\begin{array}{c}\text { TOTAL } \\
\left(\mathrm{M}^{2}\right)\end{array}$ \\
\hline & R. Meeting & 10 orang & 3 & 2 & 20 \\
\hline & Pantry & 4 orang & 2 & 1,5 & 12 \\
\hline \multirow[t]{2}{*}{ Service } & Toilet & 3 orang & 4 & 3 & 36 \\
\hline & Gudang & 2 orang & 3 & 4 & 24 \\
\hline \multirow[t]{3}{*}{ Parkir } & Parkir Mobil & & 10 & 15 & 150 \\
\hline & Parkir Motor & & 50 & 2 & 100 \\
\hline & Loading in/out & & 2 & 18 & 36 \\
\hline \multirow[t]{4}{*}{ Teknis } & R. Mekanikal & 5 orang & 3 & & \\
\hline & R. Elektrikal & & 3 & & \\
\hline & R. Monitoring & & 3 & 3 & 45 \\
\hline & R. Genset & & & & \\
\hline \multirow[t]{2}{*}{ Operasional } & Gudang Mesin & & 1 & 80 & 30 \\
\hline & R. Alat & & 1 & 30 & 30 \\
\hline TOTAL & & & & & 3887 \\
\hline TOTAL + SIRKULASI 20\% & & & & & 4664 \\
\hline
\end{tabular}

Sumber : Penulis, 2021

Program yang digunakan dalam mengolah sampah terbagi menjadi 3 jenis, yaitu mengubah sampah menjadi barang baru yang berguna, mengubah sampah menjadi pupuk, dan mengubah sampah menjadi energi untuk bangunan. Sehingga pengolahan sampah pada proyek ini mengutamakan prinsip tidak menyisakan sampah ataupun bentuk buangan lainnya.

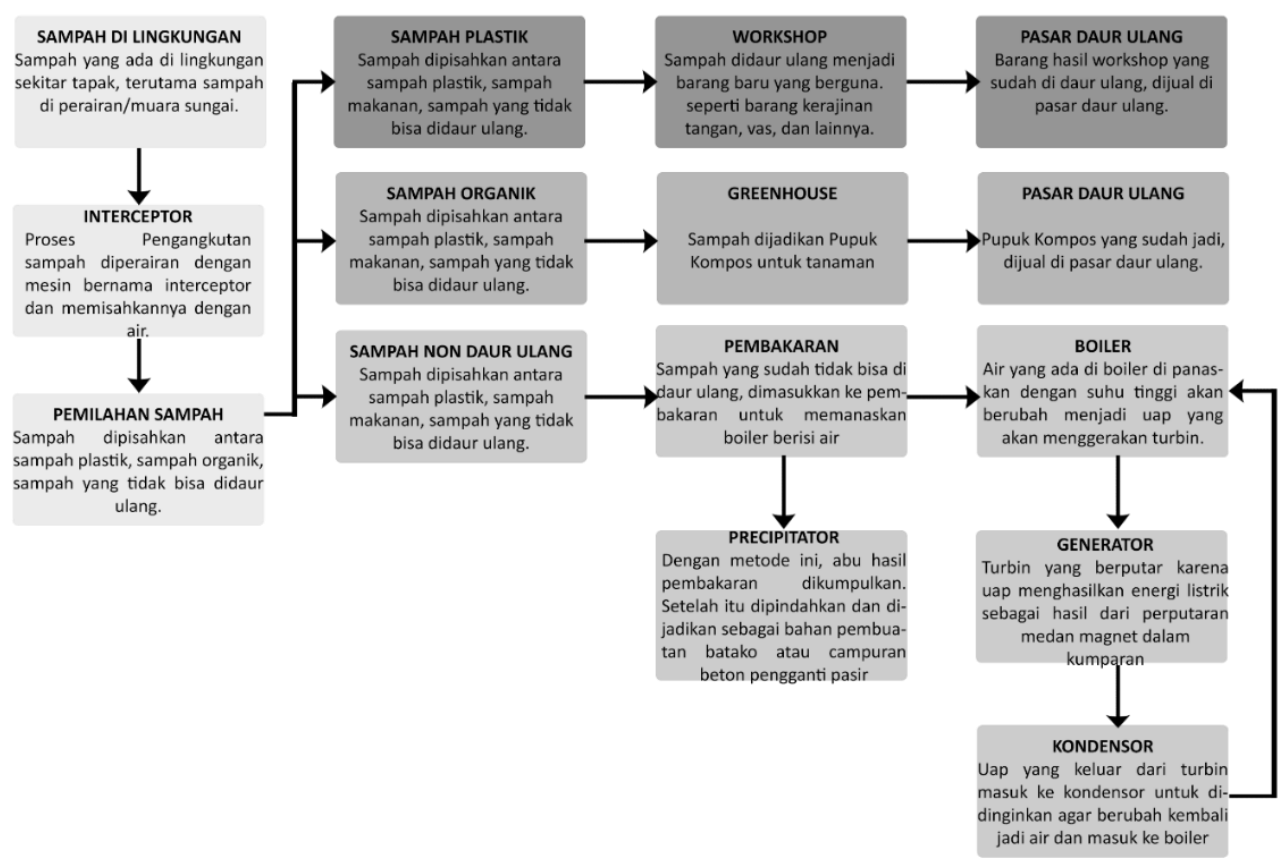

Gambar 3. Alur Pengolahan Sampah pada Proyek Sumber : Penulis, 2021

Konsep pada bangunan ini didukung dengan program ruang, analisis matahari, analisis angin, analisis kebisingan, analisis orientasi view, analisis akses, dan juga analisis simpul sekitar tapak. Sehingga diperoleh zonasi dan luasan yang dibutuhkan pada proyek ini. 


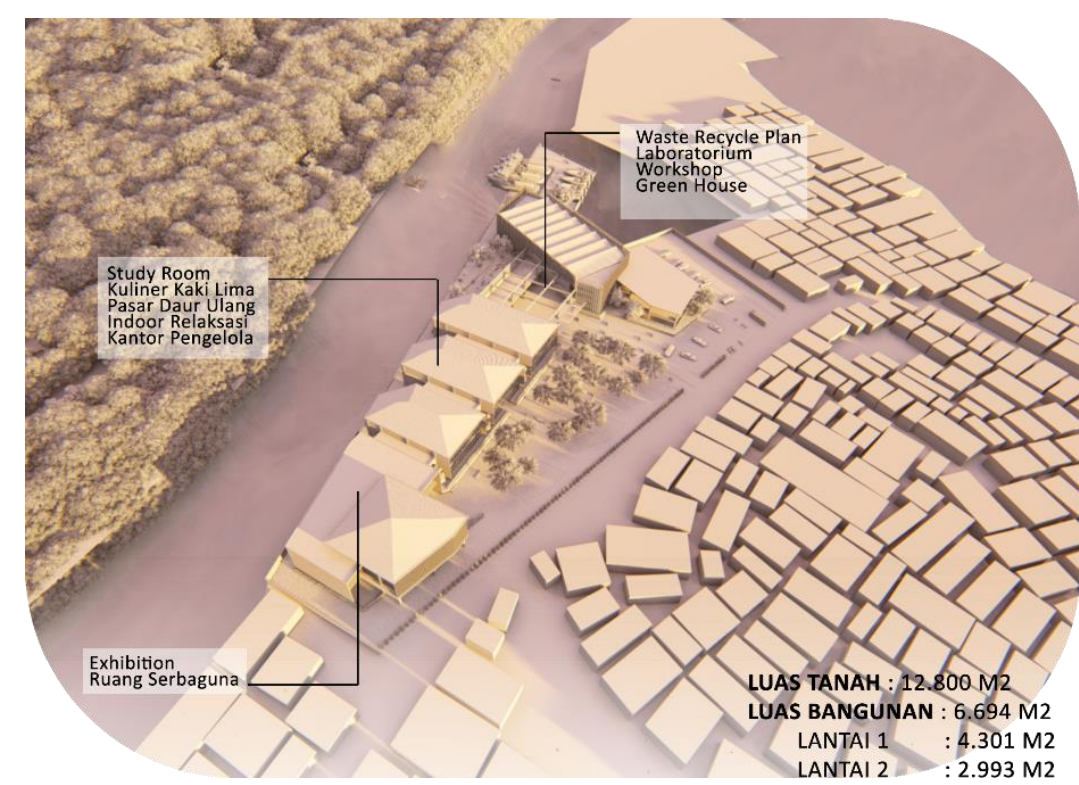

Gambar 4. Program - program di setiap Zonasi

Sumber : Penulis, 2021

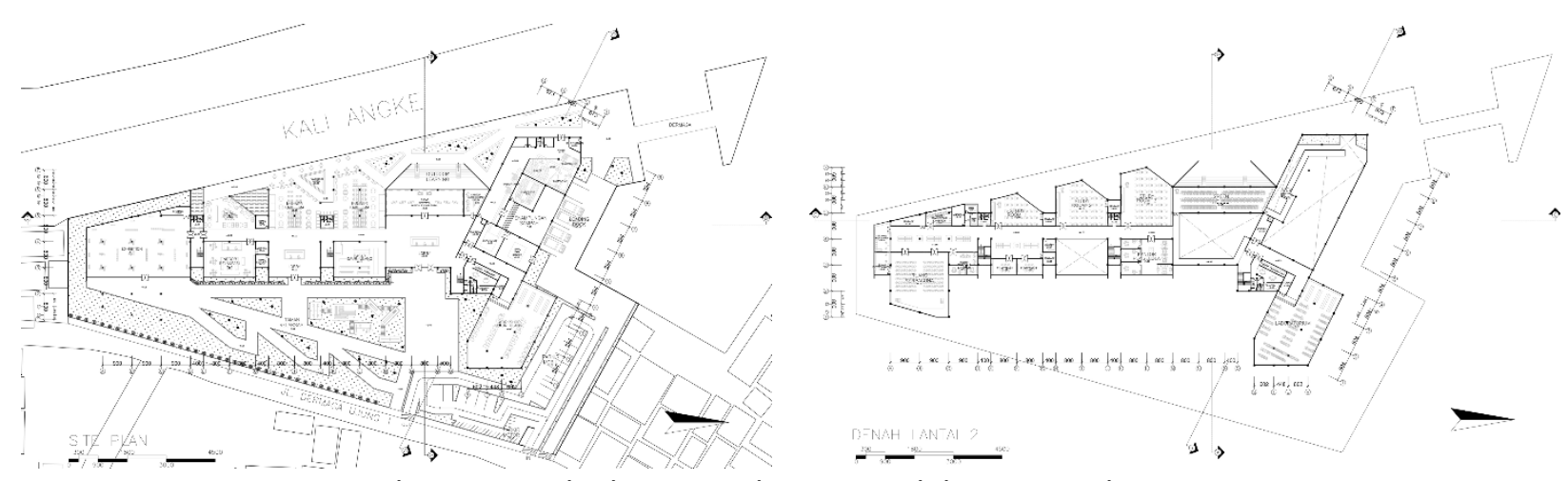

Gambar 5. Denah Skema Fasilitas Pengolahan Sampah

Sumber : Penulis, 2021

Bangunan di bagi menjadi 3 bagian dari sisi selatan ke sisi utara. Pada sisi utara, terdapat bangunan utama yaitu Bangunan Pengolahan Sampah. Pada sisi tengah, terdapat bangunan publik dan pada sisi selatan, terdapat bangunan edukasi.

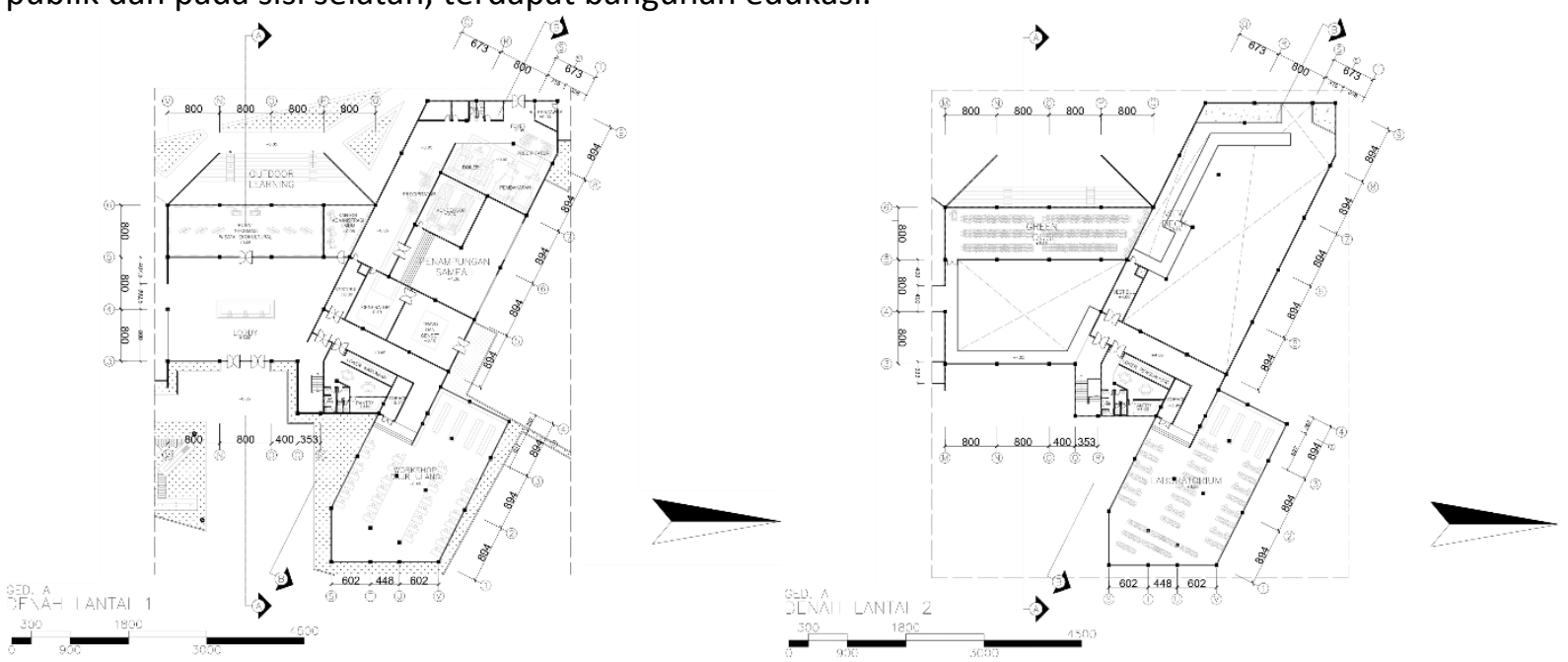

Gambar 6. Denah Gedung A. Fasilitas Pengolahan Sampah

Sumber : Penulis, 2021 


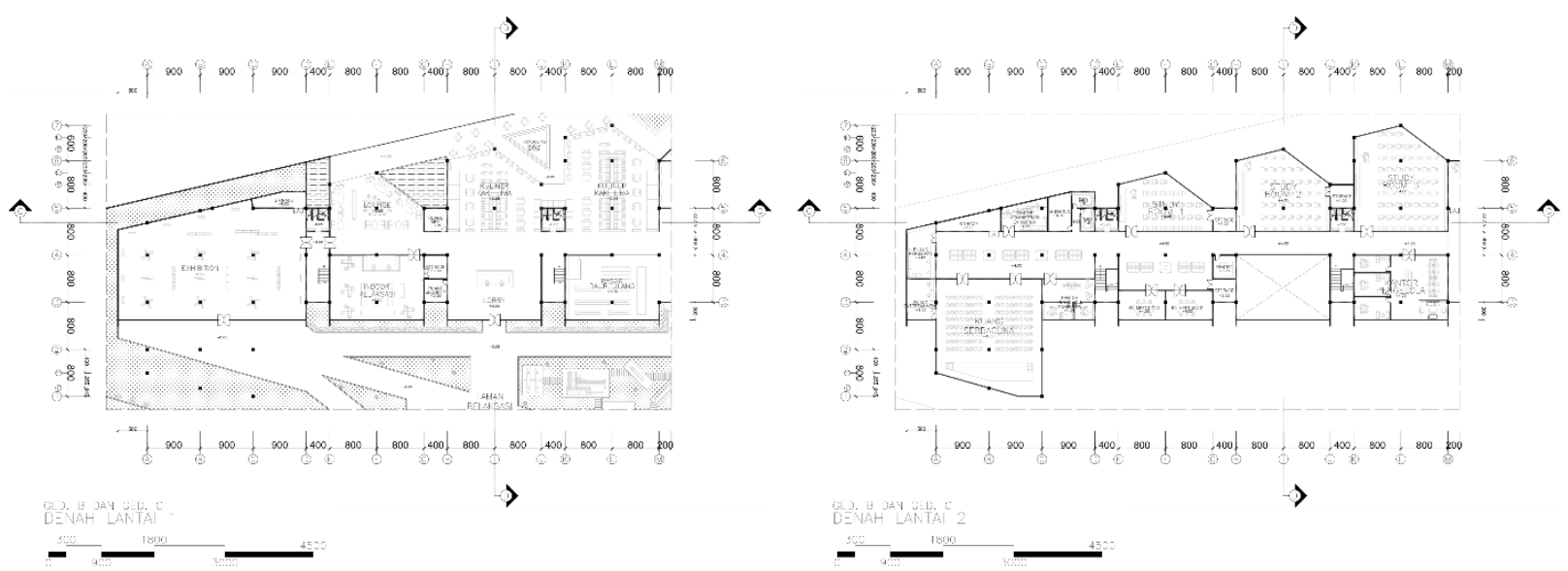

Gambar 7. Denah Gedung B dan C. Fasilitas Pengolahan Sampah

Sumber : Penulis, 2021

Penerapan Konsep Bangunan Arsitektur Teknologi Tinggi/High-Tech Architecture dengan Pemanfaatan Bangunan Nol Limbah/Zerowaste Building pada Eksterior dan Interior Bangunan
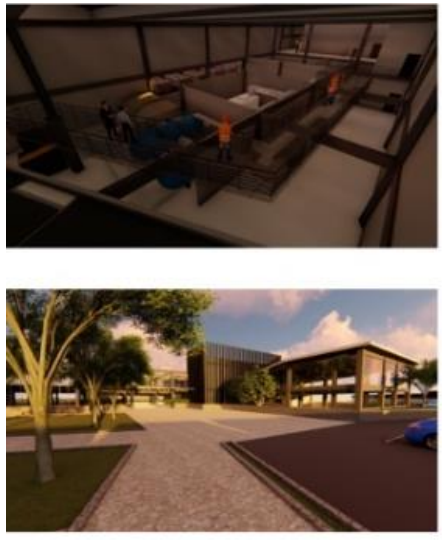

INSIDE OUT
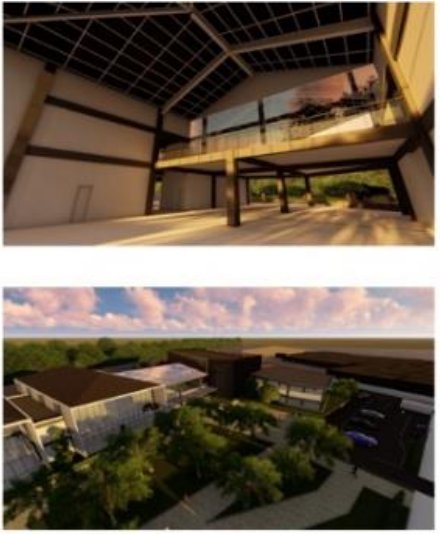

CELEBRATION OF PROCESS
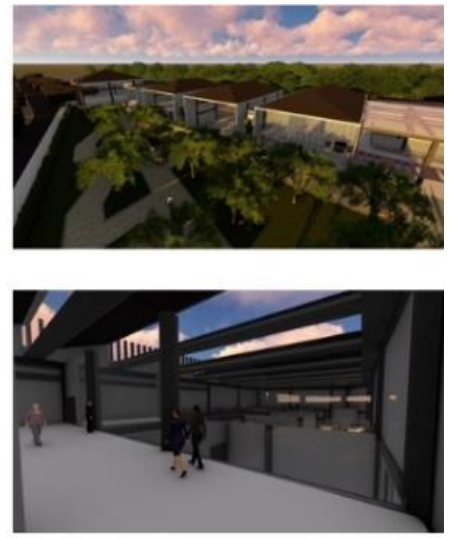

TRANSPARENCY, LAYERING MOVEMENT

Gambar 8. 3 dari 6 Kriteria High-Tech Architecture; inside out, celebration of process, dan transparency-layering-movement

Sumber : Penulis, 2021

Kriteria Inside Out menekankan pada memperlihatkan struktur dan utilitas bangunan sehingga proses dari pengolahan sampah dan aplikasi nya pada bangunan dapat dilihat oleh publik. Kriteria Celebration of Process menunjukkan bagaimana suatu bangunan dapat berdiri dengan konstruksi-konstruksinya. Sedangkan Transparency,Layering,Movement memperlihatkan bagaimana bangunan tersebut terlihat transparan dan berlapis sesuai dengan proses dan fungsi yang terdapat pada proyek ini. 

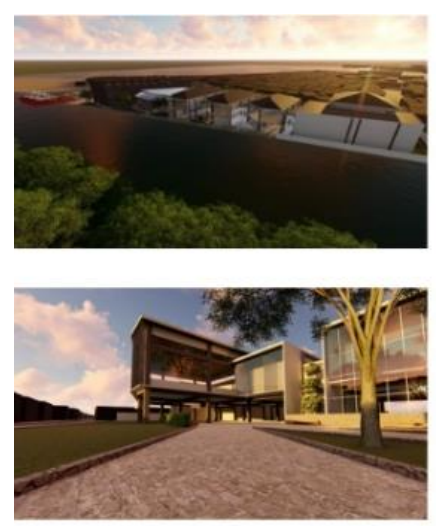

FLAT BRIGHT COLOR
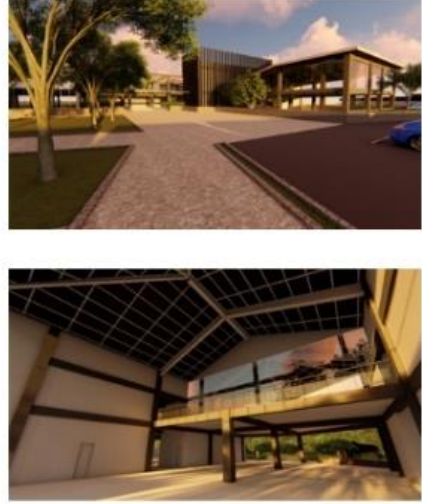

A LIGHTWEIGHT FILIGREE OF TENSILE MEMBER
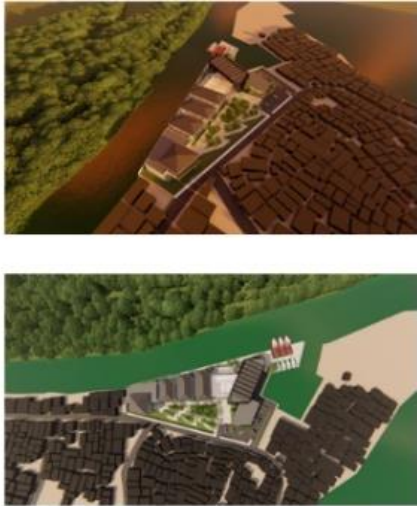

OPTIMISTIC CONFIDENCE IN SCIENTIFIC CULTURE

Gambar 9. 3 dari 6 Kriteria High-Tech Architecture; flat bright color, a lighweight filigree of tensile member, dan optimistic confidence in scientific culture.

Sumber : Penulis, 2021

Kriteria Flat Bright Color merupakan penggunaan warna yang dominan ke warna terang seperti putih atau abu-abu. Kriteria A Lightweight Filigree of Tensile Member memperlihatkan pada penggunaan material yang ringan, tidak menyebabkan sampah dan mudah didapat. Sedangkan Optimistic Confidence in Scientific Culture memperlihatkan bagaimana bangunan tersebut dapat menyatu, beradaptasi dan mengajak masyarakat sekitar untuk ikutserta beraktivitas dan menyelesaikan permasalahan ekologis sampah yang terjadi di kawasan Muara Angke.

Untuk 3 kriteria lain seperti Effienciency, Impermanency-Flexibility, dan Lower-Energy terlihat dari bagaimana ruang - ruang dan program dari bangunan tersebut dibentuk. Seperti ruang ruang besar yang bisa dialih fungsikan serta program pengolahan sampah yang dibakar menjadi energi listrik bangunan itu sendiri.

\section{KESIMPULAN DAN SARAN Kesimpulan}

Perencanaan proyek fasilitas pengolahan sampah di Muara Angke yang menggunakan metode pragmatis, kontekstual dengan pendekatan Arsitektur High-Tech berfokus pada pengolahan sampah tanpa menghasilkan buangan lainnya (zerowaste) serta edukasi dan pemenuh kebutuhan lainnya bagi masyarakat sekitar. Penggunaan metode ini, bertujuan untuk memberikan sebuah fasilitas pengolahan sampah dengan menerapkan prinsip "zerowaste" yang efektif dan hemat energi dengan menggunakan beberapa sistem energi olahan mandiri di dalam bangunan. Selain itu, penerapan kontekstual pada bangunan ini diharapkan dapat menjadi pusat aktivitas masyarakat sekitar kawasan dan menimbulkan dampak yang baik bagi penyelesaian permasalahan ekologis sampah yang terjadi di kawasan Muara Angke. Visualisasi Arsitektur High-Tech pada bangunan ikut serta mempengaruhi aktivitas untuk memberikan edukasi tentang sampah bagi masyarakat kawasan Muara Angke.

Dari proyek ini didapati bahwa perlu adanya data dan analisis yang mendalam untuk memecahkan permasalahan ekologis yang ada. Sehingga dari data dan analisis tersebut didapat hasil yang akan dimunculkan dalam bentuk. Kemudian metode perancangan disesuaikan dengan permasalahan yang diangkat berdampingan dengan pendekatan-pendekatan lainnya yang diperlukan untuk mendukung metode yang dipilih. Sehingga bisa menghasilkan bangunan yang efektif dan efisien serta menjawab permasalahan ekologis tersebut. 


\section{Saran}

Terlepas dari pendekatan dan metode yang digunakan pada fasilitas pengolahan sampah ini setiap perancang disarankan untuk melakukan kajian yang lebih mendalam terkait data - data yang diperlukan untuk menjawab isu yang akan diangkat. Seperti contohnya dalam isu pengolahan sampah ini diperlukan data seperti presentase jenis sampah yang menumpuk, cara - cara menanggulangi berbagai jenis sampah, keadaan konteksktual kawasan, serta siklus aktivitas penduduk sekitar. Setelah itu perancang dapat menentukan program - program dan besaran yang diperlukan dengan memperhatikan alur sirkulasi aktivitas, efektifitas dan efisiensi melalui berbagai jenis pendekatan atau konsep yang akan diangkat untuk menjawab isu ekologis.

\section{REFERENSI}

Anggara, S. (2018). Ekologi Administrasi: Holistik, Kontemporer, dan Kontekstual;. In S. Anggara, Ekologi Administrasi: Holistik, Kontemporer, dan Kontekstual; (pp. 1-5). Bandung: CV Pustaka Setia.

Asmoro, B. B. (2015). Landasan Konseptual Perencanaan dan Perancangan Observatorium dan Museum Antariksa di Kabupaten Gunung Kidul. Tinjauan Teori Arsitektur High-Tech, 6877.

Calvin, J. (2019). Napak Tilas Isu Sampah Plastik dan Bahayanya. Kompasiana.

Davies, C. (1988). High-Tech Architecture. New York: Rizolli.

Ensiklopedia IPTEK. (2007). Ensiklopedia Sains untuk Pelajar dan Umum. In E. IPTEK, Ensiklopedia Sains untuk Pelajar dan Umum (p. 436). Jakarta: Lentera Abadi.

Frederic E. Clements, V. E. (1939). Bio-Ecology. New York: John Wiley \& Sons.

Hayat, H. Z. (2018). Model Inovasi Pengelolahan Sampah Rumah Tangga, 131-141.

Hutagalung RA. (2010). Ekologi Dasar. In H. R., Ekologi Dasar (pp. 13-15). Jakarta: Bumi Aksara.

Jomarkka, K. (2003). Design Method Birkh + Nuser Architecture. In K. Jomarkka, Design Method Birkh + Nuser Architecture (pp. 62-65). Berlin: Birkhäuser Architecture.

Sitorus, R. (2019). Pemerintah RI Perkirakan Sampah Laut 0,25 -0,59 Juta Ton per Tahun. Bisnis.com.

Suryono, K. E. (2017). Konsep Pendekatan Arsitektur. Penerapan Analogi Linguistik pada Arsitektur dengan Menggunakan Prinsip Seni Ekspresionis, 26.

Susanto. (2017). Ekologi:Konservasi Sumber Daya Hayati. In Susanto, Ekologi:Konservasi Sumber Daya Hayati (pp. 1-9). Purwokerto: UMP Press.

Sutanto, A. (2020). Peta Metode Desain. In A. Sutanto, Peta Metode Desain (pp. 171-178). Jakarta: Universitas Tarumanagara.

Suyud Warno Utomo, d. (2014). Pengertian, Ruang Lingkup Ekologi, dan Ekosistem. In d. Suyud Warno Utomo, Ekologi (p. 3). Jakarta: Universitas Terbuka.

Tim Kamus Bahasa Indonesia. (2008). Sampah. In Kamus Bahasa Indonesia (p. 1353). Jakarta: Pusat Bahasa.

Winata, S. (2021, Januari). Eco-Logic. (S. Winata, Performer) Microsoft Teams, West Jakarta, DKI Jakarta, Indonesia.

Ambari, M. (2017, September 2018). Sampah Plastik Semakin Ancam Laut Indonesia. Retrieved from Mongabay: https://www.mongabay.co.id/2017/09/18/sampah-plastik-semakinancam-laut-indonesia-seperti-apa/

Ambari, M. (2018, Juli 26). Ancaman Sampah Plastik untuk Ekosistem Laut Harus Segera Dihentikan. Retrieved from Mongabay: https://www.mongabay.co.id/2018/07/26/ancaman-sampah-plastik-untuk-ekosistemlaut-harus-segera-dihentikan-bagaimana-caranya/

Biro Komunikasi. (2017, Agustus 19). PBB Verifikasi 16.056 Nama Pulau Indonesia. Retrieved from Kementrian Kordinator Bidang Kemaritiman dan Investasi: https://maritim.go.id/pbb-verifikasi-16-056-nama-pulau-indonesia/ 
Environmental Defense Fund. (1998, Juli 15). From The Ecological X-Files: Proof Aliens are Destroying Endangered Species. Retrieved from Environmental Defense Fund: https://www.edf.org/news/ecological-x-files-proof-aliens-are-destroying-endangeredspecies

Jakarta Smart City. (2018). Berbagai Cara untuk Menanggulangi Sampah Ibukota. Retrieved from Jakarta Smart City: https://smartcity.jakarta.go.id/blog/326/berbagai-cara-untukmenanggulangi-sampah-ibukota

Kementrian Pendidikan dan Kebudayaan Republik Indonesia. (2016). Ekologi. Retrieved from KBBI Daring: https://kbbi.kemdikbud.go.id/entri/ekologi

Kementrian Pendidikan dan Kebudayaan Republik Indonesia. (2016). Ekosistem. Retrieved from KBBI Daring: https://kbbi.kemdikbud.go.id/entri/ekosistem

Kementrian Pendidikan dan Kebudayaan Republik Indonesia. (2016). Habitat. Retrieved from KBBI Daring: https://kbbi.kemdikbud.go.id/entri/habitat

Lurgi, M. (n.d.). Kehilangan Habitat Tidak Hanya Mempengaruhi Spesies, Ini Memengaruhi Jaringan Hubungan Ekologis. Retrieved from Innerself Climate Impact: https://id.climateimpactnews.com/solutions/environmental/2204-habitat-loss-doesn-tjust-affect-species-it-impacts-networks-of-ecological-relationships

Masdar. (2020). Pencemaran Laut. Retrieved from Kementrian Kelautan dan Perikanan: https://kkp.go.id/djprl/bpsplpadang/page/1053-pencemaran-laut

National Geographic Indonesia. (2019, Maret 5). 9 Ancaman Terbesar yang Dihadapi Laut dan Isinya Akibat Ulah Manusia. Retrieved from National Geographic Indonesia: https://nationalgeographic.grid.id/read/131656602/9-ancaman-terbesar-yang-dihadapilaut-dan-isinya-akibat-ulah-manusia

Nikko, S. (2019, Juni 13). Pengertian Habitat, Jenis, dan Contoh Habitat di Sekitar Kita. Retrieved from Pengertian Apapun: http://www.pengertianku.net/2019/06/pengertianhabitat-jenis-dan-contoh-habitat-di-sekitar-kita.html

Pendidikan.co.id. (2021, Januari 11). Pengertian Habitat. Retrieved from Pendidikan.co.id: https://pendidikan.co.id/pengertian-habitat/

Rahman, M. (2020, Juli 16). Mengenal Arsitektur High Tech dan Penerapannya pada Bangunan. Retrieved from 99.co: https://www.99.co/id/panduan/arsitektur-High-Tech

Wihardandi, A. (2012, Mei 7). Kehilangan Habitat, Ancaman Utama Hilangnya Keanekaragaman Hayati. Retrieved from Mongabay: https://www.mongabay.co.id/2012/05/07/kehilangan-habitat-ancaman-utamahilangnya-keanekaragaman-hayati-indonesia/

Wikipedia. (2021). Biodiversity Loss. Retrieved from Wikipedia: https://en.m.wikipedia.org/wiki/Biodiversity_loss

Wikipedia. (2021). Sampah. Retrieved from Wikipedia: https://id.wikipedia.org/wiki/Sampah Zakky. (n.d.). Pengertian Habitat Beserta Fungsi, Macam-Macam, dan Contohnya. Retrieved from Seluncur.id: https://www.seluncur.id/pengertian-habitat/

Zerowaste International Alliance. (2018). Zerowaste Definition. Retrieved from Zerowaste International Alliance: https://zwia.org/zero-waste-definition/ 